\title{
Graphene and the Immune System: A Romance of Many Dimensions
}

\author{
Sourav P. Mukherjee ${ }^{1}$, Massimo Bottini ${ }^{2,3}$ and Bengt Fadeel ${ }^{\text {* }}$ \\ ${ }^{1}$ Nanosafety and Nanomedicine Laboratory, Division of Molecular Toxicology, Institute of Environmental Medicine, Karolinska \\ Institutet, Stockholm, Sweden, '2Department of Experimental Medicine and Surgery, University of Rome 'Tor Vergata', Rome, \\ Italy, ${ }^{3}$ Sanford Burnham Prebys Medical Discovery Institute, La Jolla, CA, United States
}

\section{OPEN ACCESS}

Edited by:

Paola Italiani,

Consiglio Nazionale Delle

Ricerche (CNR), Italy

Reviewed by:

Seyed Moein Moghimi,

Durham University,

United Kingdom

Aldo Tagliabue,

ALTA, Italy

${ }^{*}$ Correspondence:

Bengt Fadeel

bengt.fadee/@ki.se

Specialty section:

This article was submitted to Inflammation,

a section of the journal

Frontiers in Immunology

Received: 08 April 2017

Accepted: 24 May 2017

Published: 13 June 2017

Citation:

Mukherjee SP, Bottini M and Fadeel B

(2017) Graphene and the

Immune System: A Romance of

Many Dimensions.

Front. Immunol. 8:673.

doi: 10.3389/fimmu.2017.00673
Graphene-based materials (GBMs) are emerging as attractive materials for biomedical applications. Understanding how these materials are perceived by and interact with the immune system is of fundamental importance. Phagocytosis is a major mechanism deployed by the immune system to remove pathogens, particles, and cellular debris. Here, we discuss recent studies on the interactions of GBMs with different phagocytic cells, including macrophages, neutrophils, and dendritic cells. The importance of assessing GBMs for endotoxin contamination is discussed as this may skew results. We also explore the role of the bio-corona for interactions of GBMs with immune cells. Finally, we highlight recent evidence for direct plasma membrane interactions of GBMs.

Keywords: graphene, macrophage, endotoxin, inflammasome, pattern recognition receptors

O brave new worlds, that have such people in them!

Edwin A. Abbott, Flatland. A Romance of Many Dimensions (1884).

\section{INTRODUCTION}

Graphene and its derivatives have attracted considerable attention for various applications in science and technology $(1,2)$. Graphene oxide (GO), in particular, is being intensively investigated for various biomedical applications including drug delivery and bioimaging, and as biosensors (3). GO offers interesting physicochemical properties including its large surface area, ease of surface functionalization, and superior colloidal stability in aqueous media (4). However, increasing production and use of graphene-based materials (GBMs) also necessitates careful scrutiny of the impact of such materials on cells and tissues (5). Understanding the interactions with the immune system is of particular importance (6). Once inside the body, a foreign material will encounter phagocytic cells of the innate immune system, such as neutrophils, macrophages, and dendritic cells (DCs). These cells represent the first line of defense against foreign intrusion (microorganisms, particles), and they also clear cell debris, thus playing an important role in tissue homeostasis. Macrophages are involved in the initiation, propagation, and resolution of inflammation (7), while DCs are antigen-presenting cells that act as a bridge between the innate and adaptive arms of the immune system. Neutrophils are specialized in killing bacteria and other microorganisms, although recent studies have suggested that these cells may also orchestrate adaptive immune responses (8). It is important to note that macrophages that reside in different tissues are not only important effectors of the innate immune response but may also contribute to acute or chronic tissue injury resulting from toxicant exposure through the release of a host of soluble mediators, e.g., reactive oxygen or reactive nitrogen species, proteolytic enzymes, and pro-inflammatory cytokines or chemokines (9). Thus, as emphasized before by Laskin et al. (9), macrophages are mediators of both "defense and destruction." 
Recently, a classification system (Figure 1) was proposed by researchers in the EU-funded GRAPHENE Flagship Project as a starting point for the categorization of distinct graphene types (10). In brief, three physicochemical properties of GBMs were highlighted: (i) the number of graphene layers, (ii) the average lateral dimensions, and (iii) the carbon-to-oxygen $(\mathrm{C} / \mathrm{O})$ atomic ratio; the inclusion of the $\mathrm{C} / \mathrm{O}$ ratio as a functional property can be justified by the fact that GBMs are both structurally and chemically heterogeneous. Indeed, as stated by Wick et al. (10) different members of the GBM family do not share the same "standard" surface. The surface of pristine graphene is hydrophobic while in the case of GO, surfaces consist of hydrophobic islands interspersed with hydrophilic regions. This could potentially influence the interactions of these materials with biological systems. Here, we discuss recent studies on the interaction of GBMs with cells of the innate immune system, including macrophages, neutrophils, and DCs. Notably, while these cells all share the propensity for phagocytosis, we also explore emerging evidence that GBMs may exert direct effects on the plasma membrane of immune cells in the absence of cellular uptake. The biodegradation of carbon-based materials by immune cells including neutrophils and macrophages has been highlighted in other recent review articles $(3,11,12)$ and is not discussed here. We will mainly focus our discussion on studies using macrophages or macrophage-like cell lines as there are few studies to date on GBM effects on neutrophils and DCs. Nevertheless, as more and more studies are emerging, we may begin to understand how the immune system responds to $2 \mathrm{D}$ objects-a journey into flatland.

\section{THE IMPORTANCE OF ENDOTOXIN ASSESSMENT}

Endotoxins, also known as lipopolysaccharides (LPS), are large (200-1,000 kDa), hydrophobic, heat-stable molecules that form part of the outer membrane of gram negative bacteria (13). LPS is a potent inflammatory mediator which activates immune cells via pattern recognition receptors leading to the secretion of pro-inflammatory mediators, e.g., tumor necrosis factor (TNF)- $\alpha$, and interleukin (IL)-1 $\beta$ (14). As many nanomaterial-enabled drug carriers or diagnostic devices are engineered to target the immune system (or to avoid interactions with it), it is increasingly important to understand immune response to these materials $(15,16)$. Of particular importance in this context is the fact that nano-biomaterials and pharmaceutical products alike are commonly contaminated with endotoxins which could lead to septic shock and organ failure if administered to patients (17). Endotoxin detection in pharmaceutical products is performed using two different methods. The rabbit pyrogen test (RPT) enables the detection

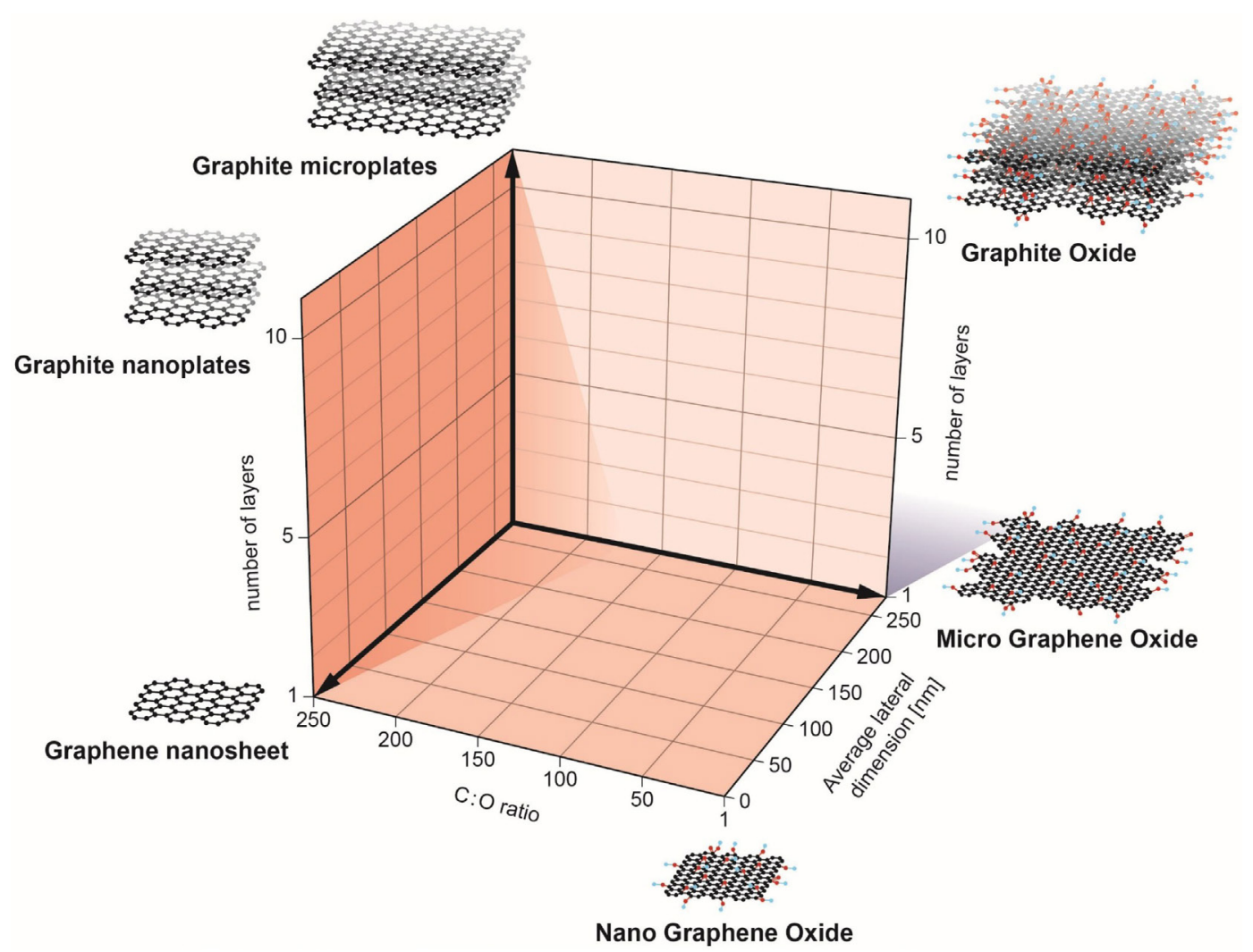

FIGURE 1 | Classification of graphene-based materials (GBM). In the European Commission funded GRAPHENE Flagship project, three physicochemical descriptors were defined to enable the classification of GBMs: number of graphene layers, average lateral dimension, and atomic carbon/oxygen ratio. The proposed classification framework will help to determine the role of specific physicochemical properties on the health and safety profile of GBMs. Reproduced from: Wick et al. (10) with permission from John Wiley \& Sons, Inc. 
of pyrogens in general by measurement of fever development after injection of the test sample; it is expensive and requires the use of large numbers of animals (18). The second type of endotoxin detection method, the Limulus amebocyte lysate (LAL) assay, is based on the blood of wild horseshoe crab populations. While the RPT assay can only detect the presence of endotoxins indirectly, the LAL assay is more specific to endotoxins as it takes advantage of the LPS-sensitive serine protease Factor C. Upon activation, Factor $\mathrm{C}$ induces a coagulation cascade leading to the amplification of the LPS stimulus and the formation of a firm gel clot. All LAL assays are in principle based on this coagulation cascade, but they have been further modified to enable quantitative determination of endotoxins (18). Both of these tests have a long history of use for traditional pharmaceuticals and medical devices and are routinely used in drug development. More recently, the recombinant factor $\mathrm{C}(\mathrm{rFC})$ assay and the macrophage activation test (MAT) were recognized as alternatives to the LAL assay. The MAT, which mimics the human fever reaction, was established as an alternative test for pyrogen testing (19). Importantly, the European Directive 2010/63/EU on the protection of animals used for scientific purposes enforces the replacement of animal tests when validated alternatives exist. While the LAL assay is known to be very sensitive, several laboratories have reported problems of interference of various types of nanomaterials with one or more of the LAL assay formats (20-22). Indeed, carbon-based nanomaterials including GBMs were shown to interfere with the LAL assay, which may lead to erroneous results or mask the effects of the materials themselves $(23,24)$. In a recent study, the authors suggested that repeated cycles of autoclaving may reduce the endotoxin content of carbon-based nanomaterials including pristine graphene and that the native versus depyrogenated materials elicited distinct macrophage responses in vitro (25). However, the chromogenic LAL assay was employed to assess for endotoxin contamination, calling into question whether the proposed depyrogenation procedure worked (25). TLR4 reporter cells were suggested as an alternative assay to evaluate endotoxin contamination of metal/ metal oxide nanoparticles (21). However, recent work has implied that GO could trigger cell death in macrophages via TLR4 (discussed below), meaning that the use of such reporter cells could also yield ambiguous results. Mukherjee et al. (23) developed a novel assay for endotoxin detection to circumvent problems with assay interferences of GBMs. The assay, designated the TNF- $\alpha$ expression test (TET), is based on the detection of TNF- $\alpha$ secretion in primary human monocyte-derived macrophages incubated in the presence or absence of a specific endotoxin inhibitor. It was shown that when non-cytotoxic doses of GBMs were applied, the TET enabled unequivocal detection of LPS with a sensitivity that was comparable to the LAL assay. Guidelines for the preparation of endotoxin-free GO were also presented (23).

\section{BIO-CORONA FORMATION: SHELTER FROM THE STORM}

When a nanomaterial is introduced into a living system it interacts with biological molecules (proteins, lipids, etc.) leading to the formation of a so-called bio-corona on the surface (26), or, to put this in immunological terms, the nanomaterial is opsonized (the process whereby pathogens or cells are rendered more susceptible to phagocytosis). Detailed studies of various types of nanoparticles have shown that bio-corona formation depends not only on the size or surface curvature of the particle but also on surface properties such as the degree of hydrophobicity (27-29). The bio-corona has been shown to modulate cellular uptake of nanomaterials (30), and a recent study suggested that proteins present in the original protein corona are retained on the nanoparticles until they reach the lysosomes (31). Moreover, the adsorption of proteins may mitigate the cytotoxic effects of nanomaterials. Indeed, in vitro studies have shown that the adsorption of serum proteins reduces the cytotoxicity of carbon nanotubes (CNTs) (32) as well as GO (33), and based on a combination of experimental and theoretical approaches, it was suggested that the bio-corona mitigates the cytotoxicity of GO by limiting its penetration into the cell membrane (34). Furthermore, modeling studies suggested that graphene, due to its hydrophobic nature, may interrupt hydrophobic protein-protein interactions (35). Indeed, it is important to recognize the differences in physicochemical properties between different members of the GBM family, not least with respect to the potential interaction with proteins. Graphene is essentially a single atomically thin sheet of $\mathrm{sp}^{2}$-bonded carbon atoms, whereas GO is an oxidized graphene sheet derivatized by carbonyl and carboxyl groups at the edges and displaying epoxide and hydroxyl groups on the basal plane (36). Moreover, graphene and GO have different surface energies-an important parameter affecting dispersibility. Thus, graphene is hydrophobic and dispersible in organic solvents whereas GO can be dispersed in water (37). The latter property derives mostly from the ionizable edge carboxyl groups, the basal plane being essentially a network of hydrophobic islands of unoxidized benzene rings surrounded by polar groups (38). Additionally, small GO sheets are more hydrophilic than larger ones because of greater charge density, which could impact on bio-interactions.

Intravenously injected nanomaterials can adsorb a wide range of proteins in the blood (39). The bio-corona of blood proteins is rapidly formed, and it has been shown to affect hemolysis and thrombocyte activation (40). Furthermore, complement activation on the surface of nanomaterials is of particular concern when it comes to clinical applications. In fact, complement proteins have been consistently identified in or on nanoparticle coronas $(28,30$, $40,41)$. The complement system is a critical component of the innate immunity in the blood; it is a proteolytic cascade typically triggered via three distinct pathways (classical, lectin, and alternative) that converge to generate the same set of effector molecules at the third component of complement (C3) (42). Complement proteins opsonize pathogens and cells for engulfment via complement receptors and could conceivably promote nanomaterial uptake as well. However, certain complement factors may instead confer "stealth" properties to nanomaterials by preventing further complement activation, as shown in a recent study on GO (43). Complement activation also liberates two potent effector molecules (C3a and $\mathrm{C} 5 \mathrm{a}$ ) that play important roles in the recruitment and activation of inflammatory cells as well as anaphylaxis, a serious allergic reaction that is rapid in onset and may cause death (44). Several reports have documented pathway-specific 
complement activation by various types of nanomaterials including carbon-based nanomaterials such as CNTs $(45,46)$ and GO $(47,48)$. The question is: could particle surfaces be engineered to avoid protein adsorption and/or unscheduled complement activation? The attachment of polymers such as poly(ethylene glycol) (PEG) on particle surfaces is a common approach in nanomedicine, and the traditional view has held that PEGylation completely prevents protein adsorption, thereby preventing the clearance of particles by the reticuloendothelial system. However, if this were true, then how does one explain complement activation on PEGylated particles? In recent years, the view has emerged that PEGylation of nanomaterials only partially blocks protein adsorption and may even promote the formation of a bio-corona that is distinct in comparison to the corona formed on pristine nanomaterials $(49,50)$. Indeed, in a recent study using macrophage-like RAW264.7 cells, the adsorption of specific proteins was shown to be required to prevent uptake of PEG- or poly(ethyl ethylene phosphate) (PEEP)-coated polystyrene particles (51).

The choice of polymer coating matters. Luo et al. (52) reported that PEG-coating prevented uptake of GO by murine peritoneal macrophages while coating with cationic poly(ether imide) (PEI) favored uptake at low doses, but compromised cell viability at high doses. In another recent study, the authors provided evidence that PEGylated GO of approximately $200 \mathrm{~nm}$ in lateral size induced immune responses (cytokine release) in murine peritoneal macrophages; interestingly, comparable levels of activation were also observed following PEGylation of the non-carbon-based 2D material, molybdenum-disulfide $\left(\mathrm{MoS}_{2}\right)$ (53). The authors speculated that integrin signaling could account for the enhanced cytokine responses in cells exposed to PEG-GO. Overall, the study suggested that PEGylation does not serve to passivate the surfaces of $2 \mathrm{D}$ materials. Xu et al. (54) prepared a series of GO derivatives including aminated $\mathrm{GO}\left(\mathrm{GO}-\mathrm{NH}_{2}\right)$, poly(acrylamide)-functionalized GO (GO-PAM), poly(acrylic acid)-functionalized GO (GO-PAA), and PEG-functionalized
GO (GO-PEG), and compared their toxicity with pristine GO. The GO materials all displayed lateral dimensions in the range of $100-500 \mathrm{~nm}$ and the $\zeta$-potential was negative for all the materials in cell culture medium due to protein adsorption. Among these GO derivatives, GO-PEG and GO-PAA induced less toxicity toward murine J774A.1 macrophage-like cells than pristine GO, and GO-PAA proved to be the most biocompatible one, both in vitro and in mice (54). The differences in biocompatibility were suggested to be due to differences in the compositions of the bio-corona, especially whether or not immunoglobulin $\mathrm{G}$ (IgG) was present; GO-PAA and GO-PEG had less IgG content in their protein coronas $(30-40 \%)$ than $\mathrm{GO}, \mathrm{GO}-\mathrm{NH}_{2}$, and $\mathrm{GO}$ PAM (50-70\%). IgG is a well-known opsonin that plays a key role in the clearance of pathogens. This study points toward strategies for safe design of $\mathrm{GO}$ for biomedical applications and underscores the importance of the bio-corona (54).

\section{EFFECTS ON MACROPHAGES: BREAKING AND ENTERING}

Macrophages ("big eaters") are professional phagocytes arising from the bone marrow; these cells are referred to as monocytes when they are present in the peripheral circulation and "macrophages" when they reside in tissues. Macrophage phagocytosis of pathogens is facilitated through opsonization by immunoglobulins and components of the complement system, but engulfment may also be non-specific. We have noted that primary human monocyte-derived macrophages efficiently engulfed GO without signs of acute $(24 \mathrm{~h}$ ) cell death (Figure 2). GO was found in membrane-enclosed vesicles in the cytoplasm, suggesting uptake via endocytosis. Other recent studies using macrophage-like THP.1 cells suggested that phagocytosis influences the degree of cytotoxicity of GO to some extent (55). However, while inhibition of phagocytosis blunted the cytotoxicity of single-layer GO, the effects of multi-layered GO were shown to be similar regardless
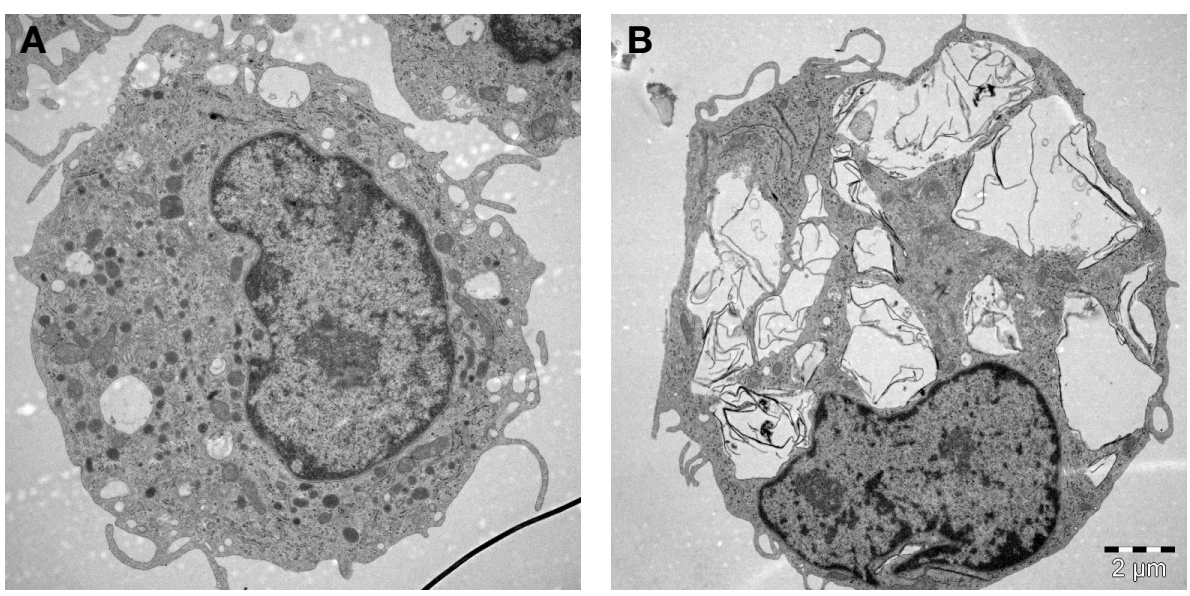

FIGURE 2 | Macrophages are professional phagocytic cells capable of ingesting micron-sized graphene oxide (GO). These TEM images show primary human monocyte-derived macrophages cultured for $24 \mathrm{~h}$ in cell medium alone (A) or with $10 \mu \mathrm{g} / \mathrm{mL} \mathrm{GO}$ (B). The cells readily internalized GO (present in cytoplasmic vesicles) without ultrastructural signs of cell death. Cells were maintained in RPMI-1640 medium supplemented with $10 \%$ fetal bovine serum. TEM: Kjell Hultenby, Electron Microscopy Core Facility, Karolinska Institutet. 
of whether or not phagocytosis occurred. Furthermore, other recent studies have reported that GO sheets with large lateral dimensions could align with the plasma membrane of macrophages (so-called "masking" effect) and it was hypothesized that this parallel arrangement of GO sheets on the cell surface could either promote their internalization, or isolate the cells from their environment, thus compromising cell viability and/or cell function (56). Similarly, Ma et al. (57) reported that large GO sheets showed a stronger "adsorption" to the plasma membrane of murine macrophage-like J774.A1 cells with less phagocytosis, while small GO sheets were more readily taken up by cells. The authors also found that large GO promoted a pro-inflammatory polarization of macrophages both in vitro and in vivo. In contrast, other investigators have reported that small GO sheets elicited more profound effects on human immune cells (monocytes) when compared to large GO (58). Li et al. (59) suggested, on the basis of experimental and theoretical studies, that micron-sized graphene sheets entered cells through membrane piercing or slicing ("edgefirst" uptake). In fact, several studies in recent years using different cell models have suggested that GO could exert direct effects on the plasma membrane of cells, with or without cell death. For instance, micron-sized GO sheets were found to induce the formation of vacuoles in the cytosolic compartment of cells leading to an increased cell membrane permeability for small molecules; this vacuolization was only observed in cells that overexpressed the water channel, aquaporin (AQP1) (60). GO was also shown to compromise plasma membrane and cytoskeletal function in various cell lines without significant signs of cell death, and interactions with integrins in the cell membrane were implicated in this process (61). The authors proposed that this could be exploited to sensitize cancer cells to chemotherapeutic agents, but it was not demonstrated whether these effects were specific for cancer cells. Furthermore, single-layer graphene was found to produce holes (pores) in the membranes of A549 lung carcinoma cells and macrophage-like RAW264.7 cells, leading to a substantial loss of cell viability (62). Pore formation occurred even in the presence of serum, and molecular dynamics simulations suggested that the pore formation was dependent on lipid extraction. Indeed, previous experimental and theoretical studies have suggested that the antibacterial behavior of graphene arises from the formation of pores in the bacterial cell wall (63), possibly due to lipid extraction from bacterial membranes (64). Finally, in another recent study, nano-sized GO sheets were shown to induce membrane ruffling in a variety of different cell lines with concomitant shedding of membrane fragments (65). The underlying mechanism was not disclosed, although changes in the levels of $\mathrm{Ca}^{2+}$ in the cell are known to regulate the formation of such actin-driven membrane protrusions. Thus, it appears that GBMs are capable of interacting with cells in a variety of different ways including masking, piercing, ruffling/shedding, pore formation (possibly via membrane lipid extraction), and/or internalization into cells. How does one make sense of such disparate observations? First of all, there could be important differences in the test material itself, including the thickness and the lateral dimensions (and, of course, the dose of the material added to cell cultures). Moreover, differences in cell culture conditions (including whether or not the cell culture medium is supplemented with serum) may come into play. Indeed, it has been noted that the composition of the cell culture medium itself could critically affect the way in which GO (and other nanomaterials) interact with cells (66). Finally, the fact that different cell models are used may account for the striking differences in cellular outcomes in the studies reported here. Thus, it is important to understand that transformed cell lines are only a model of normal cells, and that so-called macrophagelike cell lines do not fully recapitulate the behavior of primary macrophages (67). It is also important to realize that there are many different macrophage populations and that the phenotype or activation status of macrophages may affect how these cells respond to nanomaterials, as we and others have recently shown $(68,69)$. Notwithstanding, the view is emerging that GO could have direct effects on the cell membrane and further studies are needed to understand these interactions. This is obviously important if GBMs are to be used as "smart" carriers of a therapeutic payload to specific cell populations in the body.

\section{EFFECTS ON MACROPHAGES: INFLAMMASOME ACTIVATION}

Inflammasomes are multiprotein complexes that activate caspase-1, which leads to maturation and secretion of the pro-inflammatory cytokines IL-1 $\beta$ and IL-18 (70). Inflammasome activation is important for host defense and pathogen clearance. In addition, inflammasome activation is implicated in the development of various chronic inflammatory diseases, and the NLRP3 inflammasome is activated by endogenous "danger" signals such as monosodium urate, the causative agent in gout (71), and by cholesterol crystals that are present in atherosclerotic lesions (72). Moreover, an emerging body of literature shows that carbonbased nanomaterials, including long and fiber-like multi-walled CNTs $(73,74)$ as well as small, spherical carbon nano-onions (75) and hollow carbon spheres (76), are able to activate the inflammasome complex in phagocytic cells (macrophages) with subsequent secretion of IL-1 $\beta$. GO was recently shown to trigger IL-1 $\beta$ production in myeloid (THP.1) and epithelial (BEAS-2B) cells, respectively (77). We have found that GO of varying lateral dimensions triggered the inflammasome in primary human monocytederived macrophages and we noted that cellular uptake of GO was required for IL-1 $\beta$ production (Mukherjee et al., unpublished observations). Similarly, Cho et al. (55) reported that phagocytosis inhibition abolished IL- $1 \beta$ secretion in THP. 1 cells exposed to single-layer GO, but not in cells exposed to multi-layered GO. Taken together, a range of carbon-based nanomaterials including not only fiber-like materials but also spherical particles and flat materials such as GO trigger inflammasome activation. Needless to say, it is important to exclude endotoxin contamination of the test material when conducting such experiments as LPS is known to act as a co-signal for inflammasome activation (78). Indeed, endotoxin is often used to stimulate cells in vitro when assessing NLRP3 inflammasome activation (73), and this is certainly relevant in the context of a microbial challenge. However, it is pertinent to ask how the inflammasome is activated in sterile (nanomaterial) induced inflammation. In a recent publication, Jessop et al. (79) provided evidence for a role of high-mobility group box 1 (HMGB1) for MWCNT-induced inflammasome 
activation in vitro and in vivo. Cholesterol crystals are known to act as "danger" signals and a recent study demonstrated that cholesterol crystals triggered neutrophils to release neutrophil extracellular traps (NETs) (see below) which, in turn, primed macrophages for cytokine release (80). This finding suggests that a "danger" signal may drive sterile inflammation through its interaction with neutrophils. Further studies should address whether the release of HMGB1 or other "danger" signals plays a role in GO-induced inflammasome activation.

Toll-like receptors (TLRs) are so-called pattern recognition receptors that recognize structurally conserved molecules expressed by microbes, leading to the activation of immune responses (81). TLR4, the pattern recognition receptor for LPS (endotoxin), has been suggested to recognize a host of other endogenous factors, ranging from proteins to metal ions. However, direct activation of a single receptor by such a range of molecular signals is difficult to explain from a structural point of view, and care should be taken to exclude potential endotoxin contamination (82). On the other hand, it has been suggested that TLRs might sense the display of hydrophobic patches on a variety of molecules, which may explain the apparent promiscuity of this class of pattern recognition receptors (83). Interestingly, $\mathrm{Qu}$ et al. (84) reported that GO with a size of about $1-2 \mu \mathrm{m}$ induced TLR4-dependent cell death in bone marrow-derived macrophages from mice and presented evidence that this occurred, at least in part, through a paracrine $\mathrm{TNF} \alpha$-dependent mechanism. In previous work, Chen et al. (85) showed that GO induced autophagy and cytokine secretion in a TLR-dependent manner in the mouse macrophage cell line RAW264.7. In contrast, our recent studies have suggested that GO triggers inflammasome activation with secretion of IL- $1 \beta$ in primary human monocytederived macrophages without engaging the TLR signaling pathway (Mukherjee et al., unpublished results). Notably, no cell death was observed in macrophages exposed to GO, in marked contrast to the aforementioned studies. Care was taken to control for endotoxin contamination prior to cell exposures. We suggest that endotoxin testing should be mandatory when studying putative interactions of GO with TLRs.

In most of the examples provided here, the impact of GO on isolated macrophages or macrophage-like cells was investigated. While such studies may provide important insights regarding the mode of entry of GO into cells and on the signaling pathways affected following cellular interactions, studies in living organisms are needed to assess the overall response to GO and the interplay between both arms of the immune system. Shurin et al. (86) recently provided a detailed analysis of how exposure to GO modulates the allergic pulmonary response. To this end, the authors used a murine model of ovalbumin (OVA)-induced asthma, and found that GO, given at the sensitization stage, augmented airway hyperresponsiveness (AHR) and airway remodeling, while at the same time, the levels of the Th2 cytokines, IL-4, IL-5, and IL-13 were suppressed in bronchoalveolar lavage (BAL) fluid in exposed mice (86). Moreover, exposure to GO during sensitization with OVA decreased eosinophil accumulation and increased recruitment of macrophages in BAL fluid. Exposure to GO also increased the macrophage production of the mammalian chitinases, chitinase 3-like 1, and AMCase, whose expression is associated with asthma (87), and molecular modeling suggested that GO may directly interact with chitinases, affecting their activity (Figure 3). Taken together, these results indicated that pulmonary exposure to GO initiates a novel mechanism of nanomaterial-induced airway remodeling and AHR in a mouse model of asthma that is independent from eosinophilic airway inflammation and Th2-mediated immune responses, with the possible involvement of mammalian chitinases (86).

\section{EFFECTS ON NEUTROPHILS: TANGLED UP IN BLUE}

Neutrophils are the mostabundant type of whiteblood cells and play a key role in the defense against invading pathogens. Neutrophils use a variety of strategies to eliminate invading microbes: (i) microbial uptake followed by intracellular destruction through an array of proteolytic and oxidative enzymes, (ii) degranulation and secretion of antimicrobial factors such as myeloperoxidase (MPO) leading to extracellular destruction of microbes, and (iii) release of NETs with entrapment and non-phagocytic killing of microbes (88, 89). NETs consist of a network of chromatin fibers decorated with antimicrobial proteins such as neutrophil elastase (NE) and MPO to enable the extracellular killing of bacteria or fungi. Interestingly, neutrophils are apparently able to sense the size of microbes and release NETs selectively in response to large pathogens, thereby minimizing the risk of tissue damage associated with the release of NETs (90). Moreover, increasing evidence suggests that the release of NETs might also occur in non-infectious, sterile inflammation, and may contribute to tissue damage (91). For instance, crystals of monosodium urate, the causative agent of gout, were shown to induce release of NETs (92). Cholesterol crystals can also trigger NET formation, leading to priming of macrophages for cytokine release (80). Furthermore, in a very recent study, exposure to high doses of polystyrene nanoparticles and nanodiamonds triggered a "self-limiting" (resolving) NETosis-driven inflammation in mice (93). No NET formation was seen in response to large (100-1,000 nm) particles. We recently observed size-dependent triggering of NETs in primary human neutrophils exposed to GO with a more pronounced effect seen for micrometer-sized GO sheets versus GO sheets with nano-sized lateral dimensions; we also observed a disruption of lipid rafts in neutrophils incubated with GO (Mukherjee et al., unpublished results). Care was taken to control for endotoxin contamination, as LPS is known to prime neutrophils for NET production. Effects of GBMs on neutrophils in vivo could impact adversely on the innate immune defense; this remains to be studied.

\section{EFFECTS ON DENDRITIC CELLS: AIDING AND ABETTING}

DCs are professional antigen-presenting cells (94) and as such they are indispensable for the regulation of the balance between immunity (literally meaning "exemption," the capability of an organism to resist microorganisms) and tolerance (i.e., indifference or non-reactivity toward substances that would 

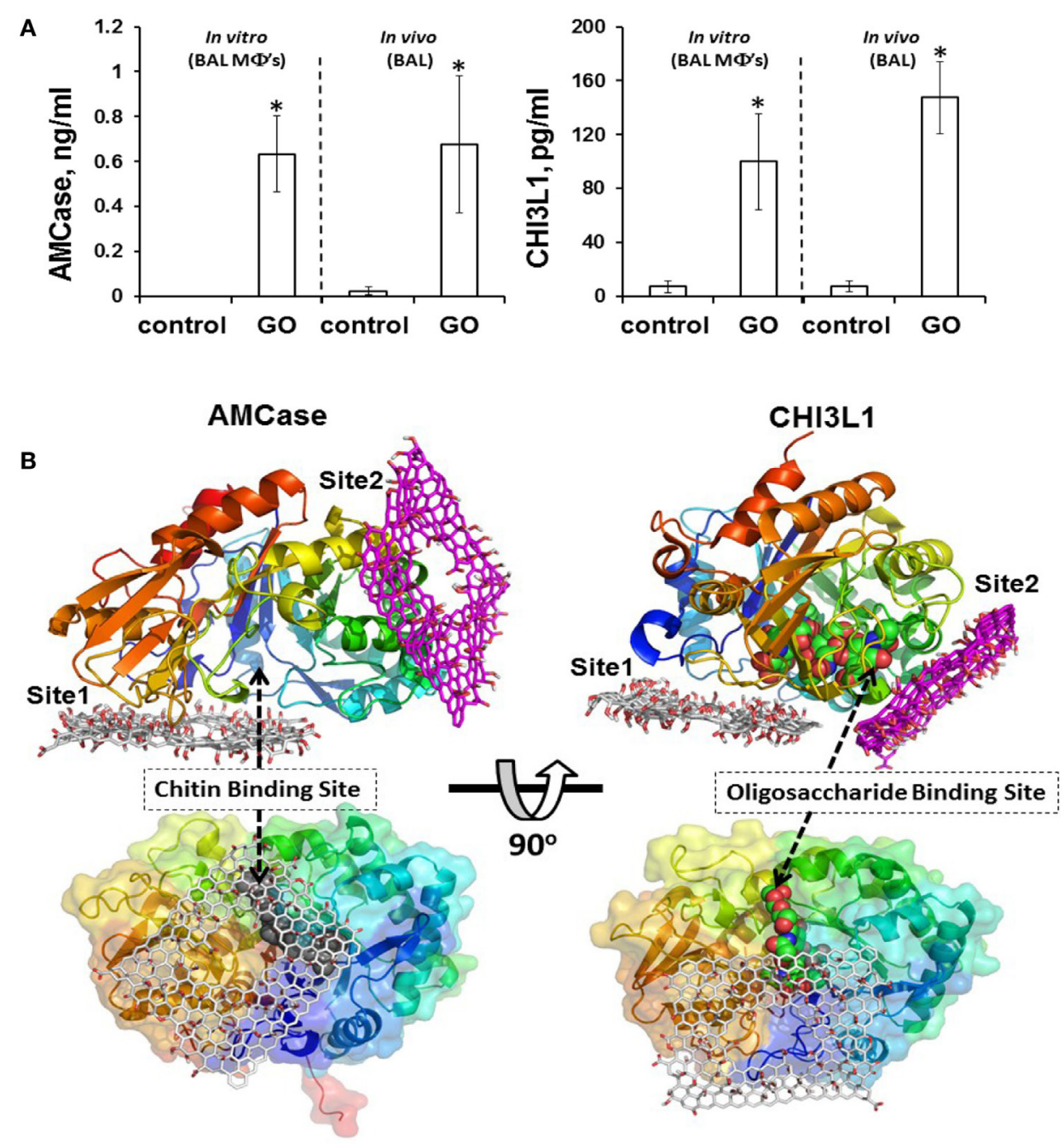

FIGURE 3 | GO triggers macrophage production of the mammalian chitinases, chitinase 3-like 1 (CHI3L1) and acidic mammalian chitinase (AMCase), whose expression is associated with asthma. (A) GO stimulates accumulation of AMCase and CHI3L1 in the lungs of mice. Levels of CHI3L1 and AMCase were measured in BAL fluid of mice 7 days after exposure to $\mathrm{GO}$, or in supernatants from cultured macrophages isolated from BAL fluid of mice exposed to GO or vehicle $24 \mathrm{~h}$ after exposure. (B) Molecular modeling suggests that GO may directly interact with chitinases. The two predicted binding sites of GO, site 1 and site 2, are shown for AMCase and $\mathrm{CHI} 3 \mathrm{~L} 1$, respectively. The occlusion of the entrance to the chitin binding site in AMCase could lead to inhibition of its activity. Reproduced from: Shurin et al. (86), with permission from The American Chemical Society.

otherwise elicit an immune response; an active rather than a passive condition). DCs take up foreign molecules as well as hostderived proteins and process them intracellularly to antigens that are presented in the context of major histocompatibility (MHC) class I and II molecules on the cell surface. In a recent in vitro study, pristine GO was found to suppress antigen presentation to T cells using OVA as a model antigen (95). DCs were exposed to GO prior to OVA-loading and then mixed with B3Z86/90.14 (B3Z) CD8+ $\mathrm{T}$ cells specific for the $\mathrm{H}-2 \mathrm{~K}^{\mathrm{b}}$-restricted antimouse OVA257-264 (SIINFEKL) peptide. Production of IL-2 was monitored as a sign of $\mathrm{T}$ cell activation upon recognition of the OVA epitope 257-264 in the context of the $\mathrm{H}-2 \mathrm{~K}^{\mathrm{b}}$ molecules (MHC class I). Interestingly, while GO also stimulated maturation of DCs, the immunosuppressive effect of GO was dominant (95). Further studies are needed to understand whether all GBMs behave in this way. In fact, as discussed below, some varieties of GO have shown promise as antigen carriers.

Commonly used adjuvants (i.e., agents that are added to a vaccine to boost the immune response toward a specific antigen) include substances such as mineral oil and alum or other inorganic compounds. However, while these compounds have been in clinical use for many years, the precise mechanism of action remains poorly understood (96). Recent studies showed that the aluminum adjuvant, alum triggered the release of IL-1 $\beta$ in macrophages and DCs in an NLRP3-dependent manner (97), and mice deficient in Nalp3 failed to mount a significant antibody response to an antigen administered with aluminum adjuvants (98). In contrast, Freund's complete and incomplete adjuvant (i.e., mineral oil with or without inactivated mycobacteria) appeared to act in an inflammasome-independent manner. 
Sun et al. (99) demonstrated that aluminum-based adjuvants can be engineered to optimize their immunostimulatory properties. Specifically, the authors synthesized a library of aluminum oxyhydroxide $(\mathrm{AlOOH})$ nanorods and compared these to commercial alum and could show that shape, crystallinity, and hydroxyl content played an important role in NLRP3 inflammasome activation (99). Rettig et al. (100) provided evidence that particle size may also influence the immune response to "danger." Using singlestranded RNA (a known "danger" signal) mixed with protamine to form particles of different sizes, the authors could show that particle size determined whether an anti-viral or anti-bacterial/ anti-fungal immune response was triggered. This was suggested to be due at least in part to the selective phagocytosis of nano-sized particles by plasmacytoid DCs, which produced interferon- $\alpha$. It will be of interest to study the potential effects of GBMs of differing lateral dimensions on DCs and whether these materials could also be exploited as adjuvants to stimulate immune responses. GBMs might also prove advantageous as antigen carriers. Li et al. (101) exploited the fact that GO can spontaneously adsorb proteins to explore the use of this material for intracellular vaccine delivery. Using an in vitro model, the authors could show that GO adsorbed proteins were efficiently internalized by DCs leading to antigen cross-presentation to CD8+ T cells. In a more recent in vivo study, polymer-modified GO (GO-PEG-PEI) with nano-scale lateral dimensions was shown to act as an antigen carrier to shuttle antigens into DCs (102). Furthermore, compared with free Helicobacter pylori Urease $\mathrm{B}$ antigen and the clinically approved aluminum adjuvant-based vaccine (Alum-Ure B), GO-PEG-PEI-Ure B was found to induce stronger cellular immunity upon intradermal administration (102). Pristine GO or GO-PEG did not show the same effect. The high surface area of GO allowing for high antigen loading capacity along with the positive charge afforded by the polymer coating could help to explain this effect. The possibility that GO per se could have adjuvant properties should also be explored, in light of the fact that small and large GO sheets trigger the NLRP3 inflammasome (discussed above). Finally, Meng et al. (103) recently reported that ultrasmall GO decorated with the antioxidant compound carnosine modulates innate immunity and improves adaptive immunity. The authors could show that GO covalently modified with carnosine, when mixed with the model antigen, OVA promoted robust and durable OVA-specific antibody responses, increased lymphocyte proliferation efficiency, and enhanced CD4+ T and CD8+ T cell activation. The authors proposed that GO-carnosine could be useful as an adjuvant to effectively enhance humoral and innate immune responses in vivo.

\section{CONCLUDING REMARKS}

In the current essay, we have highlighted recent research on the interactions of GBMs, in particular GO, with the immune

\section{REFERENCES}

1. Kostarelos K, Novoselov KS. Materials science. Exploring the interface of graphene and biology. Science (2014) 344:261-3. doi:10.1126/science.1246736

2. Ferrari AC, Bonaccorso F, Fal'ko V, Novoselov KS, Roche S, Bøggild P, et al. Science and technology roadmap for graphene, related two-dimensional system, focusing our discussion mainly on in vitro studies. While we are far from a comprehensive understanding of these interactions, one may ask whether there are any general conclusions at this point. One technical, yet non-trivial issue when performing studies of GBMs and immune-competent cells concerns the importance of knowing not only the test material (10), and whether there are traces of endotoxin as this may impact on subsequent immune responses, but also the test system, i.e., the cell model including the composition of the cell medium, and whether this is supplemented or not with serum. Furthermore, it is important to realize that the plasma membrane is not only an impassive barrier between the interior of a cell and the extracellular space but also serves as an important platform for cellular communication between cells, and between the exterior and interior of a cell (104). This is true not least for immune-competent cells that are specialized in sensing and sampling their environment. It follows from this argument that the effects of a biomaterial on the cell membrane could have ramifications for immune cell communication and function. It is of interest to note that the adjuvant, alum, was previously shown to trigger responses in DCs by altering membrane lipid structures, demonstrating that not all immune signaling is receptor mediated, and suggesting that the plasma membrane could behave as a "sensor" for solid structures (105). Thus, the impact of a biomaterial is not necessarily linked to whether or not the material is internalized as direct effects on the plasma membrane could also come into play. In the field of nanotoxicology, much time and effort has been devoted to the determination of the dose of nanoparticles delivered to and internalized by cells, but for atomically thin materials with large lateral dimensions, some toxicological outcomes may depend on direct effects on the plasma membrane, and not only on cellular uptake of the material. In other words, as we continue to probe immunological responses toward GBMs and other 2D materials, we should not forget that significant insights may come from studying seemingly superficial interactions. Or, as actress Ava Gardner once put it, "Deep down, I'm pretty superficial."

\section{AUTHOR CONTRIBUTIONS}

BF wrote the manuscript, with input from SPM and MB. The final version of the manuscript was discussed and approved by all participating authors.

\section{FUNDING}

This work was supported by grants awarded to BF by the European Commission (Flagship Project GRAPHENE, grant no. 696656) and the Swedish Research Council (grant no. 2016-02040).

crystals, and hybrid systems. Nanoscale (2015) 7(11):4598-810. doi:10.1039/ c4nr01600a

3. Bhattacharya K, Mukherjee SP, Gallud A, Burkert SC, Bistarelli S, Bellucci S, et al. Biological interactions of carbon-based nanomaterials: from coronation to degradation. Nanomedicine (2016) 12(2):333-51. doi:10.1016/j. nano.2015.11.011 
4. Bitounis D, Ali-Boucetta H, Hong BH, Min DH, Kostarelos K. Prospects and challenges of graphene in biomedical applications. Adv Mater (2013) 25(16):2258-68. doi:10.1002/adma.201203700

5. Sanchez VC, Jachak A, Hurt RH, Kane AB. Biological interactions of graphene-family nanomaterials: an interdisciplinary review. Chem Res Toxicol (2012) 25(1):15-34. doi:10.1021/tx200339h

6. Farrera C, Fadeel B. It takes two to tango: understanding the interactions between engineered nanomaterials and the immune system. Eur J Pharm Biopharm (2015) 95(Pt A):3-12. doi:10.1016/j.ejpb.2015.03.007

7. Aderem A, Underhill DM. Mechanisms of phagocytosis in macrophages. Annu Rev Immunol (1999) 17:593-623. doi:10.1146/annurev.immunol.17.1.593

8. Nathan C. Neutrophils and immunity: challenges and opportunities. Nat Rev Immunol (2006) 6(3):173-82. doi:10.1038/nri1785

9. Laskin DL, Sunil VR, Gardner CR, Laskin JD. Macrophages and tissue injury: agents of defense or destruction? Annu Rev Pharmacol Toxicol (2011) 51:267-88. doi:10.1146/annurev.pharmtox.010909.105812

10. Wick P, Louw-Gaume AE, Kucki M, Krug HF, Kostarelos K, Fadeel B, et al. Classification framework for graphene-based materials. Angew Chem Int Ed Engl (2014) 53(30):7714-8. doi:10.1002/anie.201403335

11. Kotchey GP, Hasan SA, Kapralov AA, Ha SH, Kim K, Shvedova AA, et al. A natural vanishing act: the enzyme-catalyzed degradation of carbon nanomaterials. Acc Chem Res (2012) 45(10):1770-81. doi:10.1021/ar300106h

12. Chen M, Qin X, Zeng G. Biodegradation of carbon nanotubes, graphene, and their derivatives. Trends Biotechnol (2017). doi:10.1016/j.tibtech.2016.12.001

13. Rietschel ET, Kirikae T, Schade FU, Mamat U, Schmidt G, Loppnow H, et al. Bacterial endotoxin: molecular relationships of structure to activity and function. FASEB J (1994) 8:217-25.

14. Bishop RE. Fundamentals of endotoxin structure and function. Contrib Microbiol (2005) 12:1-27. doi:10.1159/000081687

15. Vallhov H, Qin J, Johansson SM, Ahlborg N, Muhammed MA, Scheynius A, et al. The importance of an endotoxin-free environment during the production of nanoparticles used in medical applications. Nano Lett (2006) 6(8): 1682-6. doi:10.1021/nl060860z

16. Delogu LG, Stanford SM, Santelli E, Magrini A, Bergamaschi A, Motamedchaboki K, et al. Carbon nanotube-based nanocarriers: the importance of keeping it clean. J Nanosci Nanotechnol (2010) 10(8):5293-301. doi:10.1166/jnn.2010.3083

17. Dobrovolskaia MA, Germolec DR, Weaver JL. Evaluation of nanoparticle immunotoxicity. Nat Nanotechnol (2009) 4(7):411-4. doi:10.1038/nnano. 2009.175

18. Li Y, Boraschi D. Endotoxin contamination: a key element in the interpretation of nanosafety studies. Nanomedicine (Lond) (2016) 11(3):269-87. doi:10.2217/nnm.15.196

19. Hoffmann S, Peterbauer A, Schindler S, Fennrich S, Poole S, Mistry Y, et al. International validation of novel pyrogen tests based on human monocytoid cells. J Immunol Methods (2005) 298:161-73. doi:10.1016/j.jim.2005. 01.010

20. Dobrovolskaia MA, Neun BW, Clogston JD, Ding H, Ljubimova J, McNeil SE. Ambiguities in applying traditional Limulus amebocyte lysate tests to quantify endotoxin in nanoparticle formulations. Nanomedicine (Lond) (2010) 5:555-62. doi:10.2217/nnm.10.29

21. Smulders S, Kaiser JP, Zuin S, Van Landuyt KL, Golanski L, Vanoirbeek J, et al. Contamination of nanoparticles by endotoxin: evaluation of different test methods. Part Fibre Toxicol (2012) 9:41. doi:10.1186/1743-8977-9-41

22. Kucki M, Cavelius C, Kraegeloh A. Interference of silica nanoparticles with the traditional Limulus amebocyte lysate gel clot assay. Innate Immun (2014) 20:327-36. doi:10.1177/1753425913492833

23. Mukherjee SP, Lozano N, Kucki M, Del Rio-Castillo AE, Newman L, Vázquez E, et al. Detection of endotoxin contamination of graphene based materials using the TNF- $\alpha$ expression test and guidelines for endotoxin-free graphene oxide production. PLoS One (2016) 11(11):e0166816. doi:10.1371/ journal.pone. 0166816

24. Yang $\mathrm{M}$, Nie X, Meng J, Liu J, Sun Z, Xu H. Carbon nanotubes activate Limulus amebocyte lysate coagulation by interface adsorption. ACS Appl Mater Interfaces (2017) 9(10):8450-4. doi:10.1021/acsami.7b00543

25. Lahiani MH, Gokulan K, Williams K, Khodakovskaya MV, Khare S. Graphene and carbon nanotubes activate different cell surface receptors on macrophages before and after deactivation of endotoxins. J Appl Toxicol (2017). doi:10.1002/jat.3477
26. Monopoli MP, Åberg C, Salvati A, Dawson KA. Biomolecular coronas provide the biological identity of nanosized materials. Nat Nanotechnol (2012) 7(12):779-86. doi:10.1038/nnano.2012.207

27. Cedervall T, Lynch I, Lindman S, Berggård T, Thulin E, Nilsson H, et al. Understanding the nanoparticle-protein corona using methods to quantify exchange rates and affinities of proteins for nanoparticles. Proc Natl Acad Sci U S A (2007) 104(7):2050-5. doi:10.1073/pnas.0608582104

28. Lundqvist M, Stigler J, Elia G, Lynch I, Cedervall T, Dawson KA. Nanoparticle size and surface properties determine the protein corona with possible implications for biological impacts. Proc Natl Acad Sci U S A (2008) 105(38):14265-70. doi:10.1073/pnas.0805135105

29. Saha K, Rahimi M, Yazdani M, Kim ST, Moyano DF, Hou S, et al. Regulation of macrophage recognition through the interplay of nanoparticle surface functionality and protein corona. ACS Nano (2016) 10(4):4421-30. doi:10.1021/ acsnano.6b00053

30. Walkey CD, Olsen JB, Song F, Liu R, Guo H, Olsen DW, et al. Protein corona fingerprinting predicts the cellular interaction of gold and silver nanoparticles. ACS Nano (2014) 8(3):2439-55. doi:10.1021/nn406018q

31. Bertoli F, Garry D, Monopoli MP, Salvati A, Dawson KA. The intracellular destiny of the protein corona: a study on its cellular internalization and evolution. ACS Nano (2016) 10(11):10471-9. doi:10.1021/acsnano.6b06411

32. Ge C, Du J, Zhao L, Wang L, Liu Y, Li D, et al. Binding of blood proteins to carbon nanotubes reduces cytotoxicity. Proc Natl Acad Sci U S A (2011) 108(41):16968-73. doi:10.1073/pnas.1105270108

33. Chong Y, Ge C, Yang Z, Garate JA, Gu Z, Weber JK, et al. Reduced cytotoxicity of graphene nanosheets mediated by blood-protein coating. ACS Nano (2015) 9(6):5713-24. doi:10.1021/nn5066606

34. Duan G, Kang SG, Tian X, Garate JA, Zhao L, Ge C, et al. Protein corona mitigates the cytotoxicity of graphene oxide by reducing its physical interaction with cell membrane. Nanoscale (2015) 7(37):15214-24. doi:10.1039/ c5nr01839k

35. Luan B, Huynh T, Zhao L, Zhou R. Potential toxicity of graphene to cell functions via disrupting protein-protein interactions. ACS Nano (2015) 9(1): 663-9. doi:10.1021/nn506011j

36. Dreyer DR, Park S, Bielawski CW, Ruoff RS. The chemistry of graphene oxide. Chem Soc Rev (2010) 39(1):228-40. doi:10.1039/b917103g

37. Wang S, Zhang Y, Abidi N, Cabrales L. Wettability and surface free energy of graphene films. Langmuir (2009) 25(18):11078-81. doi:10.1021/ la901402f

38. Kim J, Cote LJ, Kim F, Yuan W, Shull KR, Huang J. Graphene oxide sheets at interfaces. J Am Chem Soc (2010) 132(23):8180-6. doi:10.1021/ja102777p

39. Moghimi SM, Hunter AC, Andresen TL. Factors controlling nanoparticle pharmacokinetics: an integrated analysis and perspective. Annu Rev Pharmacol Toxicol (2012) 52:481-503. doi:10.1146/annurev-pharmtox-010611-134623

40. Tenzer S, Docter D, Kuharev J, Musyanovych A, Fetz V, Hecht R, et al. Rapid formation of plasma protein corona critically affects nanoparticle pathophysiology. Nat Nanotechnol (2013) 8(10):772-81. doi:10.1038/nnano.2013.181

41. Sacchetti C, Motamedchaboki K, Magrini A, Palmieri G, Mattei M, Bernardini S, et al. Surface polyethylene glycol conformation influences the protein corona of polyethylene glycol-modified single-walled carbon nanotubes: potential implications on biological performance. ACS Nano (2013) 7(3):1974-89. doi:10.1021/nn400409h

42. Ricklin D, Hajishengallis G, Yang K, Lambris JD. Complement: a key system for immune surveillance and homeostasis. Nat Immunol (2010) 11(9):785-97. doi:10.1038/ni.1923

43. Belling JN, Jackman JA, Yorulmaz Avsar S, Park JH, Wang Y, Potroz MG, et al. Stealth immune properties of graphene oxide enabled by surface-bound complement factor H. ACS Nano (2016) 10(11):10161-72. doi:10.1021/ acsnano.6b05409

44. Moghimi SM, Andersen AJ, Hashemi SH, Lettiero B, Ahmadvand D, Hunter AC, et al. Complement activation cascade triggered by PEG-PL engineered nanomedicines and carbon nanotubes: the challenges ahead. J Control Release (2010) 146(2):175-81. doi:10.1016/j.jconrel.2010.04.003

45. Salvador-Morales C, Flahaut E, Sim E, Sloan J, Green ML, Sim RB. Complement activation and protein adsorption by carbon nanotubes. Mol Immunol (2006) 43(3):193-201. doi:10.1016/j.molimm.2005.02.006

46. Andersen AJ, Robinson JT, Dai H, Hunter AC, Andresen TL, Moghimi SM. Single-walled carbon nanotube surface control of complement recognition and activation. ACS Nano (2013) 7(2):1108-19. doi:10.1021/nn3055175 
47. Tan X, Feng L, Zhang J, Yang K, Zhang S, Liu Z, et al. Functionalization of graphene oxide generates a unique interface for selective serum protein interactions. ACS Appl Mater Interfaces (2013) 5(4):1370-7. doi:10.1021/ am302706g

48. Wibroe PP, Petersen SV, Bovet N, Laursen BW, Moghimi SM. Soluble and immobilized graphene oxide activates complement system differently dependent on surface oxidation state. Biomaterials (2016) 78:20-6. doi:10.1016/j. biomaterials.2015.11.028

49. Mahon E, Salvati A, Baldelli Bombelli F, Lynch I, Dawson KA. Designing the nanoparticle-biomolecule interface for "targeting and therapeutic delivery”. J Control Release (2012) 161(2):164-74. doi:10.1016/j.jconrel. 2012.04.009

50. Schöttler S, Landfester K, Mailänder V. Controlling the stealth effect of nanocarriers through understanding the protein corona. Angew Chem Int Ed Engl (2016) 55(31):8806-15. doi:10.1002/anie.201602233

51. Schöttler S, Becker G, Winzen S, Steinbach T, Mohr K, Landfester K, et al. Protein adsorption is required for stealth effect of poly(ethylene glycol)and poly(phosphoester)-coated nanocarriers. Nat Nanotechnol (2016) 11(4):372-7. doi:10.1038/nnano.2015.330

52. Luo N, Ni D, Yue H, Wei W, Ma G. Surface-engineered graphene navigate divergent biological outcomes toward macrophages. ACS Appl Mater Interfaces (2015) 7(9):5239-47. doi:10.1021/am5084607

53. Luo N, Weber JK, Wang S, Luan B, Yue H, Xi X, et al. PEGylated graphene oxide elicits strong immunological responses despite surface passivation. Nat Commun (2017) 8:14537. doi:10.1038/ncomms14537

54. Xu M, Zhu J, Wang F, Xiong Y, Wu Y, Wang Q, et al. Improved in vitro and in vivo biocompatibility of graphene oxide through surface modification: poly(acrylic acid)-functionalization is superior to PEGylation. ACS Nano (2016) 10(3):3267-81. doi:10.1021/acsnano.6b00539

55. Cho YC, Pak PJ, Joo YH, Lee HS, Chung N. In vitro and in vivo comparison of the immunotoxicity of single- and multi-layered graphene oxides with or without pluronic F-127. Sci Rep (2016) 6:38884. doi:10.1038/srep38884

56. Russier J, Treossi E, Scarsi A, Perrozzi F, Dumortier H, Ottaviano L, et al. Evidencing the mask effect of graphene oxide: a comparative study on primary human and murine phagocytic cells. Nanoscale (2013) 5(22):11234-47. doi:10.1039/c3nr03543c

57. Ma J, Liu R, Wang X, Liu Q, Chen Y, Valle RP, et al. Crucial role of lateral size for graphene oxide in activating macrophages and stimulating pro-inflammatory responses in cells and animals. ACS Nano (2015) 9(10):10498-515. doi:10.1021/acsnano.5b04751

58. Orecchioni M, Jasim DA, Pescatori M, Manetti R, Fozza C, Sgarrella F, et al. Molecular and genomic impact of large and small lateral dimension graphene oxide sheets on human immune cells from healthy donors. Adv Healthc Mater (2016) 5(2):276-87. doi:10.1002/adhm.201500606

59. Li Y, Yuan H, von dem Bussche A, Creighton M, Hurt RH, Kane AB, et al. Graphene microsheets enter cells through spontaneous membrane penetration at edge asperities and corner sites. Proc Natl Acad Sci U S A (2013) 110(30):12295-300. doi:10.1073/pnas.1222276110

60. Wu C, Wang C, Zheng J, Luo C, Li Y, Guo S, et al. Vacuolization in cytoplasm and cell membrane permeability enhancement triggered by micrometersized graphene oxide. ACS Nano (2015) 9(8):7913-24. doi:10.1021/acsnano. 5 b01685

61. Zhu J, Xu M, Gao M, Zhang Z, Xu Y, Xia T, et al. Graphene oxide induced perturbation to plasma membrane and cytoskeletal meshwork sensitize cancer cells to chemotherapeutic agents. ACS Nano (2017) 11(3):2637-51. doi:10.1021/acsnano.6b07311

62. Duan G, Zhang Y, Luan B, Weber JK, Zhou RW, Yang Z, et al. Graphene-induced pore formation on cell membranes. Sci Rep (2017) 7:42767. doi:10.1038/ srep42767

63. Pham VT, Truong VK, Quinn MD, Notley SM, Guo Y, Baulin VA, et al. Graphene induces formation of pores that kill spherical and rod-shaped bacteria. ACS Nano (2015) 9(8):8458-67. doi:10.1021/acsnano.5b03368

64. Tu Y, Lv M, Xiu P, Huynh T, Zhang M, Castelli M, et al. Destructive extraction of phospholipids from Escherichia coli membranes by graphene nanosheets. Nat Nanotechnol (2013) 8(8):594-601. doi:10.1038/nnano.2013.125

65. Sun C, Wakefield DL, Han Y, Muller DA, Holowka DA, Baird BA, et al. Graphene oxide nanosheets stimulate ruffling and shedding of mammalian cell plasma membranes. Chem (2016) 1(2):273-86. doi:10.1016/j.chempr. 2016.06.019
66. Bussy C, Kostarelos K. Culture media critically influence graphene oxide effects on plasma membranes. Chem (2017) 2(3):322-3. doi:10.1016/j.chempr. 2017.01.015

67. Lunov O, Syrovets T, Loos C, Beil J, Delacher M, Tron K, et al. Differential uptake of functionalized polystyrene nanoparticles by human macrophages and a monocytic cell line. ACS Nano (2011) 5(3):1657-69. doi:10.1021/ nn2000756

68. Gallud A, Bondarenko O, Feliu N, Kupferschmidt N, Atluri R, Garcia-Bennett A, et al. Macrophage activation status determines the internalization of mesoporous silica particles of different sizes: exploring the role of different pattern recognition receptors. Biomaterials (2017) 121:28-40. doi:10.1016/j.biomaterials.2016.12.029

69. MacParland SA, Tsoi KM, Ouyang B, Ma XZ, Manuel J, Fawaz A, et al. Phenotype determines nanoparticle uptake by human macrophages from liver and blood. ACS Nano (2017) 11(3):2428-43. doi:10.1021/acsnano. 6b06245

70. Broz P, Dixit VM. Inflammasomes: mechanism of assembly, regulation and signalling. Nat Rev Immunol (2016) 16:407-20. doi:10.1038/nri.2016.58

71. Martinon F, Pétrilli V, Mayor A, Tardivel A, Tschopp J. Gout-associated uric acid crystals activate the NALP3 inflammasome. Nature (2006) 440(7081):237-41. doi:10.1038/nature04516

72. Duewell P, Kono H, Rayner KJ, Sirois CM, Vladimer G, Bauernfeind FG, et al. NLRP3 inflammasomes are required for atherogenesis and activated by cholesterol crystals. Nature (2010) 464(7293):1357-61. doi:10.1038/ nature 08938

73. Palomäki J, Välimäki E, Sund J, Vippola M, Clausen PA, Jensen KA, et al. Long, needle-like carbon nanotubes and asbestos activate the NLRP3 inflammasome through a similar mechanism. ACS Nano (2011) 5(9):6861-70. doi:10.1021/nn200595c

74. Sun B, Wang X, Ji Z, Wang M, Liao YP, Chang CH, et al. NADPH oxidasedependent NLRP3 inflammasome activation and its important role in lung fibrosis by multiwalled carbon nanotubes. Small (2015) 11(17):2087-97. doi:10.1002/smll.201402859

75. Yang M, Flavin K, Kopf I, Radics G, Hearnden CH, McManus GJ, et al. Functionalization of carbon nanoparticles modulates inflammatory cell recruitment and NLRP3 inflammasome activation. Small (2013) 9(24):4194-206. doi:10.1002/smll.201300481

76. Andón FT, Mukherjee SP, Gessner I, Wortmann L, Xiao L, Hultenby K, et al. Hollow carbon spheres trigger inflammasome-dependent IL- $1 \beta$ secretion in macrophages. Carbon N Y (2017) 113:243-51. doi:10.1016/j.carbon. 2016.11.049

77. Wang X, Duch MC, Mansukhani N, Ji Z, Liao YP, Wang M, et al. Use of a pro-fibrogenic mechanism-based predictive toxicological approach for tiered testing and decision analysis of carbonaceous nanomaterials. ACS Nano (2015) 9(3):3032-43. doi:10.1021/nn507243w

78. Bhattacharya K, Andón FT, El-Sayed R, Fadeel B. Mechanisms of carbon nanotube-induced toxicity: focus on pulmonary inflammation. Adv Drug Deliv Rev (2013) 65(15):2087-97. doi:10.1016/j.addr.2013.05.012

79. Jessop F, Holian A. Extracellular HMGB1 regulates multi-walled carbon nanotube-induced inflammation in vivo. Nanotoxicology (2015) 9(3):365-72. doi:10.3109/17435390.2014.933904

80. Warnatsch A, Ioannou M, Wang Q, Papayannopoulos V. Neutrophil extracellular traps license macrophages for cytokine production in atherosclerosis. Science (2015) 349(6245):316-20. doi:10.1126/science.aaa8064

81. Gay NJ, Symmons MF, Gangloff M, Bryant CE. Assembly and localization of toll-like receptor signalling complexes. Nat Rev Immunol (2014) 14(8): 546-58. doi:10.1038/nri3713

82. Manček-Keber M, Jerala R. Postulates for validating TLR4 agonists. Eur J Immunol (2015) 45(2):356-70. doi:10.1002/eji.201444462

83. Seong SY, Matzinger P. Hydrophobicity: an ancient damage-associated molecular pattern that initiates innate immune responses. Nat Rev Immunol (2004) 4(6):469-78. doi:10.1038/nri1372

84. Qu G, Liu S, Zhang S, Wang L, Wang X, Sun B, et al. Graphene oxide induces toll-like receptor 4 (TLR4)-dependent necrosis in macrophages. ACS Nano (2013) 7(7):5732-45. doi:10.1021/nn402330b

85. Chen GY, Yang HJ, Lu CH, Chao YC, Hwang SM, Chen CL, et al. Simultaneous induction of autophagy and toll-like receptor signaling pathways by graphene oxide. Biomaterials (2012) 33(27):6559-69. doi:10.1016/j. biomaterials.2012.05.064 
86. Shurin MR, Yanamala N, Kisin ER, Tkach AV, Shurin GV, Murray AR, et al. Graphene oxide attenuates Th2-type immune responses, but augments airway remodeling and hyperresponsiveness in a murine model of asthma. ACS Nano (2014) 8(6):5585-99. doi:10.1021/nn406454u

87. Zhu Z, Zheng T, Homer RJ, Kim YK, Chen NY, Cohn L, et al. Acidic mammalian chitinase in asthmatic Th2 inflammation and IL-13 pathway activation. Science (2004) 304(5677):1678-82. doi:10.1126/science.1095336

88. Brinkmann V, Reichard U, Goosmann C, Fauler B, Uhlemann Y, Weiss DS, et al. Neutrophil extracellular traps kill bacteria. Science (2004) 303(5663):1532-5. doi:10.1126/science.1092385

89. Papayannopoulos V, Zychlinsky A. NETs: a new strategy for using old weapons. Trends Immunol (2009) 30(11):513-21. doi:10.1016/j.it.2009.07.011

90. Branzk N, Lubojemska A, Hardison SE, Wang Q, Gutierrez MG, Brown GD, et al. Neutrophils sense microbe size and selectively release neutrophil extracellular traps in response to large pathogens. Nat Immunol (2014) 15(11):1017-25. doi:10.1038/ni.2987

91. Jorch SK, Kubes P. An emerging role for neutrophil extracellular traps in noninfectious disease. Nat Med (2017) 23(3):279-87. doi:10.1038/nm.4294

92. Schauer C, Janko C, Munoz LE, Zhao Y, Kienhöfer D, Frey B, et al. Aggregated neutrophil extracellular traps limit inflammation by degrading cytokines and chemokines. Nat Med (2014) 20(5):511-7. doi:10.1038/nm.3547

93. Muñoz LE, Bilyy R, Biermann MH, Kienhöfer D, Maueröder C, Hahn J, et al. Nanoparticles size-dependently initiate self-limiting NETosis-driven inflammation. Proc Natl Acad Sci US A (2016) 113(40):E5856-65. doi:10.1073/ pnas. 1602230113

94. Steinman RM. Decisions about dendritic cells: past, present, and future. Annu RevImmunol (2012) 30:1-22. doi:10.1146/annurev-immunol-100311-102839

95. Tkach AV, Yanamala N, Stanley S, Shurin MR, Shurin GV, Kisin ER, et al. Graphene oxide, but not fullerenes, targets immunoproteasomes and suppresses antigen presentation by dendritic cells. Small (2013) 9(9-10): 1686-90. doi:10.1002/smll.201201546

96. De Gregorio E, Tritto E, Rappuoli R. Alum adjuvanticity: unraveling a century old mystery. Eur J Immunol (2008) 38(8):2068-71. doi:10.1002/eji. 200838648

97. Kool M, Pétrilli V, De Smedt T, Rolaz A, Hammad H, van Nimwegen M, et al. Cutting edge: alum adjuvant stimulates inflammatory dendritic cells through activation of the NALP3 inflammasome. J Immunol (2008) 181(6):3755-9. doi:10.4049/jimmunol.181.6.3755
98. Eisenbarth SC, Colegio OR, O'Connor W, Sutterwala FS, Flavell RA. Crucial role for the Nalp3 inflammasome in the immunostimulatory properties of aluminium adjuvants. Nature (2008) 453(7198):1122-6. doi:10.1038/nature06939

99. Sun B, Ji Z, Liao YP, Wang M, Wang X, Dong J, et al. Engineering an effective immune adjuvant by designed control of shape and crystallinity of aluminum oxyhydroxide nanoparticles. ACS Nano (2013) 7(12):10834-49. doi:10.1021/ $\mathrm{nn} 404211 \mathrm{j}$

100. Rettig L, Haen SP, Bittermann AG, von Boehmer L, Curioni A, Krämer SD, et al. Particle size and activation threshold: a new dimension of danger signaling. Blood (2010) 115(22):4533-41. doi:10.1182/blood-2009-11-247817

101. Li H, Fierens K, Zhang Z, Vanparijs N, Schuijs MJ, Van Steendam K, et al. Spontaneous protein adsorption on graphene oxide nanosheets allowing efficient intracellular vaccine protein delivery. ACS Appl Mater Interfaces (2016) 8(2):1147-55. doi:10.1021/acsami.5b08963

102. Xu L, Xiang J, Liu Y, Xu J, Luo Y, Feng L, et al. Functionalized graphene oxide serves as a novel vaccine nano-adjuvant for robust stimulation of cellular immunity. Nanoscale (2016) 8(6):3785-95. doi:10.1039/c5nr09208f

103. Meng C, Zhi X, Li C, Li C, Chen Z, Qiu X, et al. Graphene oxides decorated with carnosine as an adjuvant to modulate innate immune and improve adaptive immunity in vivo. ACS Nano (2016) 10(2):2203-13. doi:10.1021/ acsnano.5b06750

104. Lingwood D, Simons K. Lipid rafts as a membrane-organizing principle. Science (2010) 327(5961):46-50. doi:10.1126/science.1174621

105. Flach TL, Ng G, Hari A, Desrosiers MD, Zhang P, Ward SM, et al. Alum interaction with dendritic cell membrane lipids is essential for its adjuvanticity. Nat Med (2011) 17(4):479-87. doi:10.1038/nm.2306

Conflict of Interest Statement: The authors declare that the research was conducted in the absence of any commercial or financial relationships that could be construed as a potential conflict of interest.

Copyright (C) 2017 Mukherjee, Bottini and Fadeel. This is an open-access article distributed under the terms of the Creative Commons Attribution License (CC BY). The use, distribution or reproduction in other forums is permitted, provided the original author(s) or licensor are credited and that the original publication in this journal is cited, in accordance with accepted academic practice. No use, distribution or reproduction is permitted which does not comply with these terms. 